\title{
Effect of body weight training plus low carbohydrate diet versus running plus low carbohydrate diet on body fat percentage changes in overweight and obese young man
}

\section{DOI:10.36909/jer.ASSEEE.16061}

\author{
Reshandi Nugraha*, Adang Suherman, Hamidie Ronald D. Ray and Amung Ma'mun
}

Faculty of Sport and Health Education, Universitas Pendidikan Indonesia, Jl. Dr. Setiabudi no

229, Bandung 40154, Indonesia.

*Corresponding Author: reshandi@upi.edu

\begin{abstract}
This study aims to determine the effect of body weight training combined with a low carbohydrate diet and running combined with a low carbohydrate diet on reducing body fat percentage in overweight and obese young man. The research used pretest posttest group design experimental method. The sample consisted of 30 young man divided into two groups that had been strictly selected. Their body fat percentage was measured before and after the research program. The result was analyzed through paired sample t-test at a significance level of $\alpha 0.05$ and the average difference test (independent sample t-test posttest) to get a better result. This study shows that body weight training combined with a low carbohydrate diet and running combined with a low carbohydrate diet have a significant effect on decreasing body fat percentage, but running combined with a low carbohydrate diet is better at reducing body fat percentage compared with body weight training combined with a low carbohydrate diet. Overweight and obese young man can apply body weight training combined with a low carbohydrate diet or run combined with a low carbohydrate diet to reduce body fat percentage, but to get the results of a reduction in body fat percentage running and low carbohydrate diets is more recommended.
\end{abstract}

Key words: body weight training; running; low carbohydrate diet; body fat percentage; overweight and obesity young man. 


\section{INTRODUCTION}

Obesity has become an epidemic in many countries, studies show that obesity can be experienced by children, young man, to adults (Wang et al., 2002). The proportion of the obesity epidemic in children to adults has increased (Klein et al., 2004). Several studies have shown that a person who is overweight in childhood tends to be overweight in adulthood than children who are thin. About half of young man who are overweight and more than one third of children who are overweight continue to be overweight and even obese as adults (Trudeau et al., 2004). Therefore, it is urged to overcome obesity as early as possible in children and young man due to obesity in children and young man can cause various diseases including hypertension, diabetes, and cardiovascular disease (Ross et al., 2000). Even obesity is more associated with morbidity than smoking, alcoholism, and poverty If trends this continues, obesity can outperform cigarette abuse as a leading cause of preventable death (Artham et al., 2009).

Overweight is defined as a body mass index (BMI) of 25 to $29.9 \mathrm{~kg} / \mathrm{m} 2$, while obesity as a body mass index (BMI) $30 \mathrm{~kg} / \mathrm{m} 2$. Other indices that can be used and are more predictive in determining obesity include body fat, waist circumference (WC), waist to hip ratio (WHR), and weight to height ratio (Litwin, 2008). Body fat percentage can be measured using bioelectric impedance analysis (BIA) from foot to foot measured using Tanita's body composition analyzer (Minderico et al., 2008). A study shows that Tanita BC 418-MA has a very good level of reliability and is equivalent to skinfold thickness in measuring body fat so that it can identify the percentage of body fat from overweight or obese person (Kelly \& Metcalfe, 2012).

Overweight and obesity in young man are related to lifestyle, which includes lack of physical activity and eating an excessive amount of calories (Park et al., 2003). Several studies have shown that aerobic exercise is effective to prevent and treat overweight and obesity (Wei et al., 2011). However, other studies report that weight training is also effective for overweight 
and obesity treatment especially in increasing lean body mass (Akter et al., 2017). Exercise alone is not an effective method for reducing body fat percentage in overweight and obese sufferers (Ross et al., 2000). Recent research results indicate that a combination of weight training and diet can reduce body fat percentage in overweight and obese sufferers (Nugraha et al., 2020). Although there have been many studies on exercise and diet to reduce body fat percentage, hitherto there has been no research to reduce body fat percentage by applying a simple exercise model that can be done at home or anywhere without using special equipment.

Body weight training and running are two simple exercises that can be done anywhere. Both of these exercises have different characteristics, body weight training including anaerobic exercise in which the energy production process does not require oxygen with relatively short movement characteristics, such as 20 reps of squats (Sigal et al., 2007). Whereas running includes aerobic exercise in which its energy production process requires oxygen with relatively long motion characteristics, for example running for 30 minutes (Mandic et al., 2009). Both of these exercises have practical and economical value so that they can be used as choices for overweight and obese sufferers in reducing their body fat percentage.

Diet is one of the factors that has an influence in reducing body fat percentage in overweight and obese sufferers. Research shows that low carbohydrate diets are more effective than low fat diets in reducing body fat mass in overweight and obese sufferers (Brehm et al., 2003). The results of other studies show that the combination of exercise and diet clinically can reduce body fat significantly (Sigal et al., 2014). We hypothesize that the combination of body weight training with a low carbohydrate diet or a combination of running with a low carbohydrate diet can significantly reduce the percentage of body fat in overweight and obese young man. But running with a low carbohydrate diet has more effect on reducing body fat percentage than body weight training with a low carbohydrate diet. 


\section{METHODS}

\section{Participant}

Participants are university male students aged 18 to 19 years who were overweight and obese with a body mass index of more than $28 \mathrm{~kg} / \mathrm{m} 2$, a body fat percentage above $30 \%$, a waist circumference greater than $100 \mathrm{~cm}$ and a stable body weight $(2 \mathrm{~kg})$ for the past 6 months. All participants first went through screening with a predetermined flow before becoming a research sample (Figure 1). The first plot in determining the sample of this study was the examination of blood pressure, height and weight, body mass index, body fat percentage, and waist circumference. Of all 123 participants, 25 people did not take part in the examination stage because they were not interested in becoming a sample in this study, so only 98 participants took the examination stage. The results were 56 people meeting the criteria for the study. The next step was to randomly determine 56 people into two research groups; the experimental group 1 and the experimental group 2. The experimental group 1 received the body weight training and low carbohydrate diet treatment, while the experimental group 2 received the running treatment and low carbohydrate diet. All participants gave written their informed consent. After the participants filled out the agreement, only 30 participants agreed to participate in the study, 5 resigned due to breathing problems, 4 resigned because they had a history of fractures, 17 resigned because they could not commit to participate in and complete the research program. This research was conducted in accordance with ethical guidelines from the Indonesian University of Education.

\section{Intervention}

For 6 weeks, each experimental group received prescribed exercise and diet guidelines. The experimental group 1 received body weight training and low carbohydrate diet program, the body weight training program was carried out 3 times a week for 8 weeks by following the exercise guidelines given and reported every session through video. The body weight training program was divided into 3 training targets including; total body program, lower 
body program, and upper body program. The training in the first session was the total body program covering all the muscles in the legs, back muscles, chest muscles, shoulder muscles, arm muscles, and abdominal muscles. The movement of body weight training, total body program among them are squats, lunges, pull up alternatives, push-ups, shoulder push-ups, shoulder tap push-ups, crunches, and leg raises. The exercise in the second session was the lower body program by training gluteus maximus, quadriceps, hamstring, and calves. Lower body program body weight training movements include squats, lunges, side lunges, sumo squats, wall sit, and calf raises. Exercise in the third session was the upper body program with targeted muscle training included back muscles, chest muscles, shoulder muscles, arm muscles, and abdominal muscles. Upper body weight training body movements include; alternative pull ups, wide grip pushups, close grip pushups, pushups and rotations, shoulder pushups, backups, planks, and side planks. The three training sessions in the first week are repeated in the same order until the sixth week. The first week to the second week each movement is done as much as 3 sets, the movements are calculated based on repetition carried out as many as 15 repetitions, while the movements are calculated using time carried out for 30 seconds, and after completing one movement interspersed with rest for 45 seconds. Additional training load is given in the third week to the fourth week, namely by adding repetition of each movement to 20 reps, adding time to 45 minutes for the movement which is calculated based on time. Whereas the rest period after completing one move is still 45 seconds. The additional training load is given again in the fifth week until the sixth week by reducing the rest time after completing one move to 30 seconds, while the amount of reduction and the time for the movements calculated by time are still the same as before.

The experimental group 2 received the running intervention given 3 times a week for eight weeks by covering the specified distance as in training guide. Participants reported their completion using various running applications that include distance and travel time weekly. in the first week and second week, participants must complete $3-\mathrm{km}$ running not more than 
20 minutes, in the third week and fourth week participants must complete 4-km running not more than 25 minutes, the addition of running distance and running time are given in the fifth week and sixth week with $5 \mathrm{Km}$ distance and travel time not more than 30 minutes, the addition of running distance and the last travel time are given the seventh week to the eighth week with the running distance that must be traveled as far as $6 \mathrm{Km}$ and travel time not more than 35 minutes.

The dietary intervention in this study was the low carbohydrate diet, both experimental groups received this diet treatment. Low carbohydrate diet given to participants by taking into account the macronutrient nutritional composition of approximately 1500 calories consisting of $20 \%$ carbohydrate, $50 \%$ protein, and $30 \%$ fat. Carbohydrates given in this diet are oatmeal and brown rice. The protein given is chicken breast, egg white, and dory fish. And the fats given in this diet are avocados and nuts. Low carbohydrate diet was given 3 times a day; breakfast, lunch, and dinner. All diet programs were provided by researchers from Monday to Friday by providing food for breakfast, oatmeal and egg whites, while lunch and dinner were sent to each participant residence. On Saturdays and Sundays the low carbohydrate diet program was not provided by the researchers but participants follow the dietary guidelines by applying nutritional composition that have been determined but they can choose the food in accordance with the dietary guidelines. 


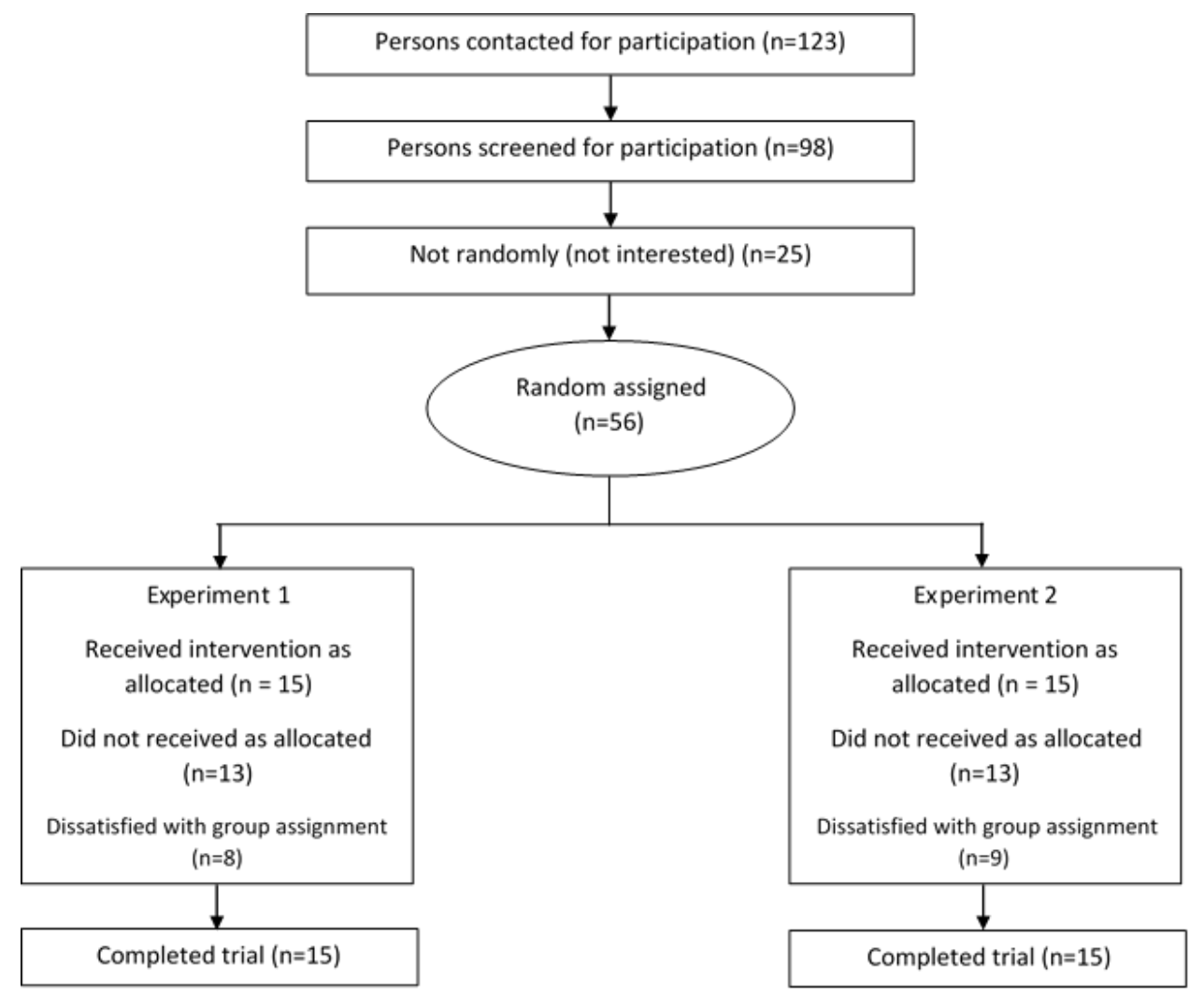

Figure 1 Flow of participants through the stud.

\section{Instrument}

Measurement of the participant's body fat percentage was carried out 2 times, at the beginning and at the end after all six-week treatments. The implementation of body fat percentage measurement was carried out in the morning starting from 07.00 to 09.00 . The instrument used to measure body fat percentage was Tanita BC-418MA. The procedure of Tanita BC-418MA was by first manually inputing gender, age, height, and body type. Furthermore, participants wore light clothing, stood tall with bare feet on the analyzer for a few seconds. After the measurement, Tanita BC-418MA provided data on the estimated body fat percentage (Jiménez et al., 2012).

\section{Statistical Analysis}

Data obtained from pre-test and post-test were then analyzed using SPSS software version 24. The first step was to test for data normal distribution and homogeneity. The data was then processed to look for the effect of each variable by using paired sample t-test at a significance level of $\alpha 0.05$. Meanwhile, to get a better influence independent sample t-test was also carried out. 


\section{RESULTS AND DISCUSSION}

\section{Results}

The results of paired sample t-test calculations in the experimental group 1 in table 1 obtained a significance value of $0.00<0.05$. This means that body weight training and low carbohydrate diet significantly influence the reduction in body fat percentage, with an average reduction in body fat percentage of $3.14 \%$.

Table 1 Summary paired sample t-test of experimental group 1

\begin{tabular}{|c|c|c|c|}
\hline \multirow{2}{*}{$\begin{array}{l}\text { Experimental Group } 1 \\
\text { Paired Sample t-test }\end{array}$} & \multicolumn{2}{|c|}{ Paired Differences } & \multirow{2}{*}{$\begin{array}{l}\text { Significance } \\
\text { (2-tailed) }\end{array}$} \\
\hline & Mean & Std. Deviation & \\
\hline $\begin{array}{l}\text { Pre-test body fat mass } \\
\text { Post-test body fat mass }\end{array}$ & 3.14 & 0.23 & 0.000 \\
\hline
\end{tabular}

The results of the paired sample t-test calculation in the experimental group 2 in table 2 show a significance value of $0.00<0.05$. So, it can be concluded that running and low carbohydrate diet significantly influence the reduction in body fat percentage, with a decrease in body fat percentage of $3.56 \%$.

Table 2 Summary paired sample t-test of experimental group 2

\begin{tabular}{|l|l|l|l|}
\hline Experimental Group 2 & \multicolumn{2}{|l|}{ Paired Differences } & Significance \\
\cline { 2 - 3 } Paired Sample t-test & Mean & Std. Deviation & \\
\hline $\begin{array}{l}\text { Pre-test body fat mass } \\
\text { Post-test body fat mass }\end{array}$ & 3.56 & 0.18 & 0.000 \\
\hline
\end{tabular}

Table 3 Summary of Independent Sample t-test

\begin{tabular}{|l|l|l|}
\hline \multirow{2}{*}{ Independent Sample t-test } & \multicolumn{2}{|l|}{ t-test for equality of means } \\
\cline { 2 - 3 } & $\mathrm{T}$ & Information \\
\hline Experimental group 1 & 12.35 & \\
\hline Experimental group 2 & 14.15 & $\mathrm{H}_{\mathrm{o}}$ Rejected \\
\hline
\end{tabular}

The results of the independent sample t-test calculation of the two experimental groups in table 3 show that the t-test value of the experimental group 1 is 12.35 while that of the experimental group 2 is 14.15 . The experimental group 2 outscored experimental group 1 . 
This implies running exercises and low carbohydrate diet have more influence in reducing body fat percentage than body weight training and low carbohydrate diets.

\section{Discussion}

To our knowledge, this is the first randomized trial to study the effects of simple anaerobic and aerobic exercises by regulating food intake in adolescents with overweight and obesity. The main finding in this study is that these two simple exercise models have a significant effect on reducing body fat percentage in overweight and obese adolescents. These findings are consistent with some previous findings that show a decrease in body fat percentage through aerobic exercise and anaerobic exercise done 3 times a week (Lee et al, 2012), a moderate decrease in body fat percentage in HEARTY trials through aerobic exercise, exercise weights, and a combination of aerobic exercise and weights in adolescents suffering from obesity (Sigal et al., 2014), the addition of three weekly sessions of aerobic exercise, weight training, and joint training gives better results than just dieting in reducing body fat percentage (Said et al., 2020). Statistical analysis of the two experimental groups showed significant results in decreasing body fat percentage, but the experimental group 2 who received running exercises and low carbohydrate diet was more significant in decreasing body fat percentage than the experimental group 1 who received body weight training and low carbohydrate diet treatments. These findings are in line with studies of the effects of aerobic exercise, weight training, versus the control group who did not exercise, the results of which show aerobic exercise can reduce fat percentage by $2.6 \%$, weight training can reduce the percentage of good fat by $2.5 \%$ compared to the control group (Lee et al, 2012). To conclude, aerobic exercise can reduce body fat percentage better than anaerobic exercise.

\section{CONCLUSION}

Body weight training combined with a low carbohydrate diet and running combined with a low carbohydrate diet significantly influence the reduction in body fat percentage. Running combined with a low carbohydrate diet is more influential in reducing body fat percentage 
compared with body weight training combined with a low carbohydrate diet. Overweight and obese young man can apply body weight training combined with a low carbohydrate diet or run combined with a low carbohydrate diet to reduce body fat percentage, but to get the results of a reduction in body fat percentage running and low carbohydrate diets is more recommended.

\section{ACKNOWLEDGEMENTS}

I want to express my sincere thanks to Mr. Adang suherman, Mr. Hamidie Ronald Daniel Ray, and Mr. Amung Ma'mun as my mentor who has supported my research. In addition, thank you for all the participants who have been willing to help this research.

\section{REFERENCES}

Akter, S., Goto, A., \& Mizoue, T. 2017. Smoking and the risk of type 2 diabetes in Japan: a systematic review and meta-analysis. Journal of epidemiology, 27(12), 553-561.

Artham, S. M., Lavie, C. J., Milani, R. V., \& Ventura, H. O. 2009. Obesity and hypertension, heart failure, and coronary heart disease-risk factor, paradox, and recommendations for weight loss. Ochsner Journal, 9(3), 124-132.

Brehm, B. J., Seeley, R. J., Daniels, S. R., \& D’Alessio, D. A. 2003. A randomized trial comparing a very low carbohydrate diet and a calorie-restricted low fat diet on body weight and cardiovascular risk factors in healthy women. The Journal of Clinical Endocrinology \& Metabolism, 88(4), 1617-1623.

Jiménez, A., Omaña, W., Flores, L., Coves, M. J., Bellido, D., Perea, V., \& Vidal, J. 2012. Prediction of whole-body and segmental body composition by bioelectrical impedance in morbidly obese subjects. Obesity surgery, 22(4), 587-593. 
Kelly, J. S., \& Metcalfe, J. 2012. Validity and Reliability of Body Composition Analysis Using the Tanita BC418-MA. Journal of Exercise Physiology Online, 15(6).

Klein, S., Burke, L. E., Bray, G. A., Blair, S., Allison, D. B., Pi-Sunyer, X., ... \& Eckel, R. H. 2004. Clinical implications of obesity with specific focus on cardiovascular disease: a statement for professionals from the American Heart Association Council on Nutrition, Physical Activity, and Metabolism: endorsed by the American College of Cardiology Foundation. Circulation, 110(18), 2952-2967.

Lee, S., Bacha, F., Hannon, T., Kuk, J. L., Boesch, C., \& Arslanian, S. 2012. Effects of aerobic versus resistance exercise without caloric restriction on abdominal fat, intrahepatic lipid, and insulin sensitivity in obese adolescent boys: a randomized, controlled trial. Diabetes, 61(11), 2787-2795.

Litwin, S. E. 2008. Which measures of obesity best predict cardiovascular risk?. J Am Coll Cardiol, 52(8), 616-619.

Mandic, S., Tymchak, W., Kim, D., Daub, B., Quinney, H. A., Taylor, D., ... \& Haykowsky, M. J. 2009. Effects of aerobic or aerobic and resistance training on cardiorespiratory and skeletal muscle function in heart failure: a randomized controlled pilot trial. Clinical rehabilitation, 23(3), 207-216.

Minderico, C. S., Silva, A. M., Keller, K., Branco, T. L., Martins, S. S., Palmeira, A. L., ... \& Sardinha, L. B. 2008. Usefulness of different techniques for measuring body composition changes during weight loss in overweight and obese women. British Journal of Nutrition, 99(2), 432-441.

Nugraha, R., Suherman, A., Ray, H. R. D., \& Ma'mun, A. 2020. The Effect of Super Set Weight Training Model and a High-Protein Diet on Body Fat Level Changes in 
Overweight and Obese Adult Men. In 4th International Conference on Sport Science, Health, and Physical Education (ICSSHPE 2019) (pp. 192-194). Atlantis Press.

Park, S. K., Park, J. H., Kwon, Y. C., Kim, H. S., Yoon, M. S., \& Park, H. T. 2003. The effect of combined aerobic and resistance exercise training on abdominal fat in obese middle-aged women. Journal of physiological anthropology and applied human science, $22(3), 129-135$.

Ross, R., Dagnone, D., Jones, P. J., Smith, H., Paddags, A., Hudson, R., \& Janssen, I. 2000. Reduction in obesity and related comorbid conditions after diet-induced weight loss or exercise-induced weight loss in men: a randomized, controlled trial. Annals of internal medicine, 133(2), 92-103.

Said, M. A., Abdelmoneem, M., Alibrahim, M. C., Elsebee, M. A., \& Kotb, A. A. H. 2020. Effects of diet versus diet plus aerobic and resistance exercise on metabolic syndrome in obese young men. Journal of Exercise Science \& Fitness, 18(3), 101-108.

Sigal, R. J., Alberga, A. S., Goldfield, G. S., Prud'homme, D., Hadjiyannakis, S., Gougeon, R., ... \& Kenny, G. P. 2014. Effects of aerobic training, resistance training, or both on percentage body fat and cardiometabolic risk markers in obese adolescents: the healthy eating aerobic and resistance training in youth randomized clinical trial. JAMA pediatrics, 168(11), 1006-1014.

Sigal, R. J., Kenny, G. P., Boulé, N. G., Wells, G. A., Prud'homme, D., Fortier, M., ... \& Jaffey, J. 2007. Effects of aerobic training, resistance training, or both on glycemic control in type 2 diabetes: a randomized trial. Annals of internal medicine, 147(6), 357-369.

Trudeau, F., Laurencelle, L., \& Shephard, R. J. 2004. Tracking of physical activity from childhood to adulthood. Medicine and science in sports and exercise, 36(11), 1937-1943. 
Wang, Y., Monteiro, C., \& Popkin, B. M. 2002. Trends of obesity and underweight in older children and adolescents in the United States, Brazil, China, and Russia. The American journal of clinical nutrition, 75(6), 971-977.

Wei, C., Yukuo, W., \& Hebei, Z. 2011. Aerobic exercise improves insulin sensitivity and lipid metabolism are associated with reduced BMI in obese adolescents. Heart, 97(Suppl 3), A105-A106. 